\title{
EFFECT OF HELICOBACTER PYLORI ERADICATIONON THE PATHOGENESIS OF MINIMAL HEPATIC ENCEPHALOPATHY IN EGYPTIAN PATIENTS WITH LIVER CIRRHOSIS
}

\section{By}

MOHIE ELDIN AMER ${ }^{1}$, MOHAMED ABDEL RASHEED ABDEL KHALIK ${ }^{1}$, MOHAMED ABDEL HAMMID BASSYONI KHEDR ${ }^{2}$ AND

SAFWAT AHMED MOHAMED ALI MASSOUD ${ }^{1^{\star}}$

Departments of Tropical Medicine ${ }^{1}$, and Clinical Pathology ${ }^{2}$, Faculty of Medicine, Al-Azhar University, Cairo ( ${ }^{*}$ Correspondence:safwatmassoud@gmail.com)

\begin{abstract}
Hepatic encephalopathy is one of the complications of liver cirrhosis. Ammonia is implicated as a precipitating factor for HE, minimal hepatic encephalopathy cannot be detected clinically and impairs quality of life, indicated that $H$. pylori infection is associated with high blood ammonia levels by urease enzyme and can lead to causation of HE. This study evaluated the effect of $H$. pylori eradication therapy on MHE.

A total of 60 cirrhotic patients were selected from al-Hussein University Hospital. They were GI: 30 patients with MHE and GII; 30 patients without MHE.

All patients were subjected to $H$. pylori stool antigen and blood ammonia level. Positive $H$. pylori patients received triple therapy for 14 days, then 4 weeks later were revaluated regarding, $H$. pylori stool antigen, serum ammonia level and NCT. Helicobacter pylori infection was found $63.3 \%$ of GI versus $40 \%$ in GII; serum ammonia levels were significantly higher in patients with GI and $H$. pylori positive. Treatment was successful in $78.9 \%$ of GI patients versus $89.4 \%$ of GII. Number connection test and serum ammonia level were significantly improved in GI patients and positive $H$. pylori after eradication therapy.
\end{abstract}

Key words: Egypt, Minimal hepatic encephalopathy, Serum ammonia, Helicobacter pylori

\section{Introduction}

Hepatic Encephalopathy (HE) is a major complication that develops in a majority of patients with liver cirrhosis. Minimal hepatic encephalopathy (MHE), the mildest form of hepatic encephalopathy is characterized by subtle motor and cognitive deficits and impairs health related to the quality of life (Dhiman et al, 2010). The Minimal Hepatic Encephalopathy (MHE) is not detectable by clinical examination although it can be detected by sensitive tests of coordination like number connection test (NCT), figure connection test (FCT) and line tracing test, electro-encephalography and visual, audit-0ory and somatosensory evoked potentials (Agrawal et al, 2011)

Among different risk factors imply-cated in the pathogenesis of $\mathrm{HE}$, hyperammonemia was found to be the most significant predictor of progression of MHE and it was widely concluded to be highly correlateed with MHE causation in both adult and pedi- atric populations (Foerster et al, 2009)

The epidemiology of $H$. pylori was very complex, different factors influencing the acquisition of $H$. pylori infection even within same geographic area (Dore and Vaira, 2003). The prevalence of infection is higher in developing countries (more than 80\%) and lower in the developed ones (less than $40 \%$ ) with a declining pattern world-wide (Azevedo et al, 2009). Valery et al. (2006) found that $H$. pylori were highly prevalent among socially and economically deprived children and poor hosing conditions were significantly associated to being infected.

Helicobacter pylori infection well known to be associated with development of precancerous lesions as chronic atrophic gastritis, or gastric intestinal metaplasia, and cancer (Watari et al, 2014). H. pylori bacteria are rich in urease enzyme that produces ammonia from urea rapidly absorbed from gastric lumen into circulation. Infection with these bacteria shown to be associated with eleva- 
ted blood ammonia levels (Vilstrup et al, 2014) and urease causing a state of diminished gastric acidity, which favored giardiasis as well (David and William, 2006).

\section{Patients and Methods}

This study was carried out at Al-Azhar University Hospitals on 60 cirrhotic patients were divided in to two groups; GI: $30 \mathrm{MHE}$ patients recognized by positive NCT. GII: 30 patients without MHE. Number connection test was a plain paper with randomly scattered number from 1-25 were connected in ascending manner within 45 seconds, any patient with NCT more than 45 second was diagnosed as MHE.

Any patient with history of proton pump inhibitors (PPI) use within last two weeks or presented with other causes of encephalopathy was excluded. The selected patients were subjected to written consent, full clinical evaluation, routine laboratory investigations and ultrasonography. Fecal $H$. pylori antigen and serum ammonia level were done before and four weeks post eradication therapy (Okuda et al, 2014).

Eradication treatment was levofloxacin $500 \mathrm{mg} /$ day, omeprazole $20 \mathrm{mg}$ twice daily and amoxicillin $1 \mathrm{~g}$ twice daily for 14 days.

Compliance with Ethical Standards: All applicable international, national, and/or institutional guidelines for the care and treating patients were followed.

\section{Results}

In the present study, the patient groups did not differ regarding age and sex (Tab. 1).

Of 60 examined patients, only ten patients were child-B; six from MHE group and four from the Non-MHE, no Child-C was involved. No differences were detected between the groups as to clinical pictures, laboratory results and/or sonographic findings.

Serum ammonia level was significantly higher in MHE patients. H. pylori was detected in 19 patients $(63.3 \%)$ and $12(40 \%)$ of MHE and Non-MHE respectively. H. pylori were eradicated in $78.9 \%$ of MHE patients and $75 \%$ of Non-MHE with no significant differences in between (Tab. 2).

Significant drop in ammonia level after $H$. pylori treatment was seen among MHE and non-MHE groups. Eradication of therapy of H. pylori dramatically improved the MHE as NCT was improved in $89.4 \%$ of MHE patients (Tab. 3).

Table 1: Groups as regard age and sex.

\begin{tabular}{|l|c|c|c|}
\hline Variable & MHE $(\mathrm{n}=30)$ & Non-MHE $(\mathrm{n}=30)$ & P value \\
\hline Age & $53.53 \pm 8.3$ & $52.73 \pm 7.75$ & $0.7(\mathrm{NS})$ \\
\hline Male /Female & $12 / 18$ & $14 / 16$ & $0.6(\mathrm{NS})$ \\
\hline
\end{tabular}

Table 2: Serum ammonia level, positive $H$. pylori and successful triple therapy in groups

\begin{tabular}{|l|c|c|c|}
\hline Items & MHE $(\mathrm{n}=30)$ & Non-MHE $(\mathrm{n}=30)$ & P value \\
\hline S. ammonia & $94.6 \pm 14.25$ & $61.13 \pm 7.5$ & $<0001(\mathrm{~S})$ \\
\hline H. pylori + ve & $19(63.3 \%)$ & $12(40 \%)$ & $0.07(\mathrm{NS})$ \\
\hline H. pylori successful therapy & $15(78.9 \%)$ & $9(75 \%)$ & $0.68(\mathrm{NS})$ \\
\hline
\end{tabular}

Table 3: Serum ammonia level andpositive NCT before and after triple therapy in $H$. pyloripatients.

\begin{tabular}{|l|c|c|c|c|}
\hline \multirow{2}{*}{} & \multicolumn{2}{|c|}{ MHE $(\mathrm{n}=19)$} & \multicolumn{2}{c|}{ Non-MHE $(\mathrm{n}-12)$} \\
\cline { 2 - 5 } & Before & After & Before & After \\
\hline S. Ammonia & $102.7 \pm 10.36$ & $80.25 \pm 8.96 *$ & $65.92 \pm 4.92$ & $55.83 \pm 4.83 *$ \\
\hline NCT +ve & $19(100 \%)$ & $2(10.5 \%) *$ & zero & \\
\hline
\end{tabular}

\section{Discussion}

Among the different risk factors implicated in the pathogenesis of the HE, hyperammonemia was found to be the commonest significant predictor of progression of MHE and it was widely concluded to be highly correlated with MHE causation in both adult and pediatric populations (Vilstrup et al, 2014). H. pylori is one of the main risk factors for HE in patients with liver cirrhosis (Yang et al, 2007). H. pylori has been suggested as possible source of ammonia production because of its high urease content (Zullo et al, 2003; 2015) 
In the present study $\mathrm{H}$. pylori infection had higher prevalence in MHE group $(63.3 \%)$ compared to non-MHE group (40\%). Although being statistically non-significant ( $\mathrm{p}=$ 0.07), these findings agreed with Agrawal et al. (2011) who found that, the prevalence was $63 \%$ and $37 \%$ in minimal and nonminimal hepatic encephalopathy groups respectively. Also, Saeed et al. (2014) reported that prevalence of $\mathrm{H}$. pylori among the MHE and Non-MHE groups of patients was 61.7 and 55\%, respectively ( $\mathrm{p}<0.05$ ). Miquel et al. (2001) found that $H$. pylori infection occurred in 22/37 (59\%) patients.

In the present study, among the MHE patients, $24(80 \%)$ were classified as Child A and $6(20 \%)$ as Child B, which agreed with Saeed et al. (2014) who reported that 58.3\% of MHE patients were classified as Child B and Agrawal et al. (2011) who found that 23\% MHE patients were Child's B.

The pre-treatment statistical evaluation of ammonia blood level was matched with the findings of NCT. Blood ammonia levels were significantly higher in MHE patients than non-MHE ones ( $p<0.001)$, and ammonia levels were significantly higher in the MHE patients with positive $H$. pylori than in MHE patients negative for $H$. pylori, so strong association between $H$. pylori infection and MHE was noticed.

In the present study, both ammonia blood levels and number connection test scores are significantly higher in $H$. pylori positive cases compared to $H$. pylori negative ones distinct from the underlying hepatic status (Chen et al, 2008; Li et al, 2013)

In the present study, H. pylori infection was eradicated in 15/19 (78.94\%) of MHE patients, this result agreed with Saeed et al. (2014) who found that H. pylori was eradicated in 29/37 (78.4\%) of MHE patients.

In the present study, there was a significant reduction in blood ammonia levels in patients with or without MHE after triple therapy $(p<0.001)$. This reduction was more marked in MHE patients compared to nonMHE ones. Thus, H. pylori contributed to development of hyperammonemia in patients with liver disease and MHE. The role of $H$. pylori in the pathogenesis of hyperammonemia was peroved in previous studies which showed a reduction in blood ammonia levels after eradication of $\mathrm{H}$. pylori infection (Chen et al, 2008; Agrawal et al, 2011). The reduction in blood ammonia levels following treatment with anti-H. pylori drugs was associated with resolution of MHE in 17 of our 19 patients with MHE and H. pylori infection with total percentage of resolution of $89.4 \%$ based on NCT score. Normalization of psychometric tests with reduction in blood ammonia levels has been reported previously, and further suggests a role of hyperammonemia in the pathogenesis of MHE (Schulz et al, 2014, Oeltzschner et al, 2015).

There were discrete reports indicating that ammonia level and/or number connection tests may not differ significantly in stable cirrhotic patients with $H$. pylori infection and hence eradication may be unnecessary (Scotiniotis et al, 2001; Kini et al, 2001; Hu et al, 2013). This discrepancy might be emphasized due to the obvious higher prevalence of $\mathrm{H}$. pylori infection in these studies compared to other studies, different eradication regimens or intrinsic differences of the population under study.

\section{Conclusion}

Helicobacter pylori infection is significantly associated with minimal hepatic encephalopathy (MHE) and eradication treatment led to the reduction in ammonia level and improvement of MHE. Thus, the patients with chronic liver disease must be screened for $H$. pylori infection and properly treated.

\section{References}

Agrawal, A, Gupta, A, Chandra, M, Koowar, S, 2011: Role of Helicobacter pylori infection in the pathogenesis of minimal hepatic encephalopathy and effect of its eradication. Indian J. Gastroenterol. 30, 1:29-32.

Azevedo, NF, Huntington, J, Goodman, KJ, 2009: The epidemiology of Helicobacter pylori and public health implications. Helicobacter 14, 1:1-7. 
Chen, SJ, Wang, LJ, Zhu, Q, Cai, JT, Chen, T, et al, 2008: Effect of $\mathrm{H}$ pylori infection and its eradication on hyperammonemia and hepatic encephalopathy in cirrhotic patients. Wld. J. Gastroenterol. 14, 13:1914-8.

David, TJ; William, AP, 2006: Markell and Voge's Medical Parasitology. $9^{\text {th }}$ edition; Saunders Elsevier, New York, USA,

Dhiman, RK, Saraswat, VA, Sharma, BK, Sarin, SK, Chawla, YK, et al, 2010: Minimal hepatic encephalopathy: Consensus statement of a working party of the Indian National Association for Study of the Liver. J. Gastroenterol. Hepatol. 25, 6:1029-41.

Dore, MP, Vaira, D, 2003: Sheep rearing and Helicobacter pylori infection, an epidemiological model of anthropozoonosis. Dig. Liver Dis. $35,1: 7-9$

Foerster, BR, Conklin, LS, Petrou, M, Barker, PB, Schwarz, KB, 2009: Minimal hepatic encephalopathy in children: evaluation with proton MR spectroscopy. Am. J. Neuroradiol. 30, 8: 34.

Hu, BL, Wang, HY, Yang, GY, 2013: Association of Helicobacter pylori infection with heaptic encephalopathy risk: A systematic review. Clin. Res. Hepatol. Gastroenterol. 37, 6:619-25.

Kini, D, Aggarwal, R, Saraswat, VA, Naik, S

R, 2001: Role of Helicobacter pylori infection in hyperammonemia and subclinical hepatic encephalopathy in cirrhosis of liver, Indian J. Gastroenterol. 20, 6:237-40.

Li, SW, Wang, K, Yu, YQ, Wang, HB, Li, YH, et al, 2013: Psychometric hepatic encephalopathy score for diagnosis of minimal hepatic encephalopathy in China. World J.Gastroenterol. 19, 46: 8745-51.

Miquel, J, Barcena, R, Boixeda, D, Fernandez, J, SanRoman, AL, et al, 2001: Role of Helicobacter pylori infection and its eradication in patients with subclinical hepatic encephalopathy. Euro J. Gastroenterol. Hepatol. 13, 9:106772.

Oeltzschner, G, Butz, M, Baumgarten, TJ, Hoogenboom, N, Wittsack, HJ, et al, 2015: Low visual cortex GABA levels in hepatic encephalopathy: links to blood ammonia, critical flicker frequency, and brain osmolytes. Metabol. Brain Dis. 30, 6:1429-38.

Okuda, M, Osaki, T, Kikuchi, S, Ueda, J, Lin, Y, et al, 2014: Evaluation of a stool antigen test using a $\mathrm{mAb}$ for native catalase for diagnosis of Helicobacter pylori infection in children and adults. J. Med. Microbiol. 63:1621-5.

Saeed, HE, Musa, NI, Safwat, E, Mohamed, S M, Elbreedy, AM, 2014: Helicobacter pylori, hyperammonemia, and hepatic encephalopathy. Egypt. Liver J. 4, 3:75-8.

Schulz, C, Schütte, K, Malfertheiner, P, 2014: Does $H$. pylori eradication therapy benefit patients with hepatic encephalopathy? Systematic review. J. Clin. Gastroenterol. 48, 6:491-9.

Scotiniotis, IA, Lucey, MR, Metz, DC, 2001: $H$. pylori infection is not associated with subclinical hepatic encephalopathy in stable cirrhotic patients. Digest. Dis. Sci. 46, 12:2744-51.

Vilstrup, H, Amodio, P, Bajaj, J, Cordoba, J, Ferenci, P, et al, 2014: Hepatic encephalopathy in chronic liver disease: 2014 practice guideline by the American Association for the Study of Liver Diseases and the European Association for the Study of the liver. Hepatol. 60:715-35.

Valery, MC, Barón, MA, Solano, L, Nadaff, G, Boccio, J, et al, 2006: Helicobacter pylori infection $\left({ }^{13} \mathrm{C}\right.$-UBT $)$, and its relationship with nutritional and socioeconomic factors in low income school children from Valencia, Venezuela. Arch. Latinoam. Nutr. 56, 4:342-9.

Watari, J, Chen, N, Amenta, PS, Fukui, H, Oshima, T, et al, 2014: Helicobacter pylori associated chronic gastritis, clinical syndromes, precancerous lesions, and pathogenesis of gastric cancer development. World J. Gastroenterol. 20, 18:5461-73.

Yang, C, Cao, S, He, X, Wang, Y, Zhang, Y, 2007: Study of correlation between Helicobacter pylori infection and hyperammonemia and hepatic encephalopathy in cirrhotic patients. Zhongguoweizhong Chinese Crit. Care Med. 19, 7: 422-4.

Zullo, A, Hassan, C, Morini, S, 2003: Helicobacter pylori infection in patients with liver cirrhosis: facts and fictions. Dig. Liver Dis. 35, 3: 197-205.

Zullo, A, De Francesco, V, Hassan, C, Morini, S, Vaira, D, 2007: The sequential therapy regimen for Helicobacter pylori eradication: A pooled-data analysis. Gut 56, 10:1353-7.

Zullo, A, Ridola, L, De Francesco, V, Hassan, C, 2015: Helicobacter pylori eradication for hepatic encephalopathy treatment. J. Clin. Gastroenterol. 49, 1:88-9. 